\title{
Stress Detection of the Employees Working in Software Houses using Fuzzy Inference
}

\author{
Rabia Abid ${ }^{1}$, Nageen Saleem², Hafiza Ammaraa Khalid ${ }^{3}$, Fahad Ahmad ${ }^{4}$, Muhammad Rizwan ${ }^{5}$, Jaweria Manzoor ${ }^{6}$, \\ Kashaf Junaid $^{7}$ \\ Computer Science Department, Kinnaird College for Women University, Lahore, Pakistan 1, 2, 3, 4, 5, 6 \\ College of Applied Medical Sciences, Jouf University, Sakaka, Kingdom of Saudi Arabia ${ }^{7}$
}

\begin{abstract}
In the modern era where the use of computer systems in software houses is mandatory and in various organizations has increased, it has given rise to the level of stress of employees working for hours at the system as well. Employees working in software houses are prone to have increased stress and anxiety level. It is important to detect the stress level of the employees so that various solutions can be applied in the working environment to get a better output. This paper would be beneficial for detecting the stress level of employees working on the computer using various inputs i.e. heart rate, pupil contraction, facial expressions, skin temperature, blood pressure, age and number of hours working on the computer. This research would indicate the raised level of stress of employees and this indication can be used to increase the yield of the quality of work and satisfaction of employees working in a particular organization. According to the levels of stress, within the working environment, during break hours various steps can be taken as a solution and applied during break hours of employees to ensure maximum satisfaction and the improved quality of work.
\end{abstract}

Keywords-Stress; fuzzy inference system; stress detection; software house

\section{INTRODUCTION}

Stress is an element which effects the human body badly physically, feeling wise or mentally. Nowadays it's the most common problem which results in significant health disease is Stress. Therefore, in this paper will discuss about the Fuzzy Logic Inference framework on which we continuously monitored the stress of patient at early stage before getting it worse, by taking the inputs parameters i.e. heartrate, pupil contraction, facial expressions, skin temperature, blood pressure, age and number of hours working on the computer.

As one of the leading threats in a person's wellbeing, stress is a risk to both health and social aspects of life [1]. It is defined as a complex reaction pattern that often has psychological, cognitive, and behavioral components [1]. Stress is also one of the main reasons behind some health related problems such as cardiovascular diseases and mental disorders [2] [3]. Stress is the reaction of any stimulus generated by the external environment considered as danger or threat. It is a mental state which affects the physical and mental health. The $21^{\text {st }}$ century has witnessed an era of $4^{\text {th }}$ generation of computing and its access to almost every individual. Employees who work in an organization especially banks and software houses had to work on computers all the day by sitting in a particular cabin. This consistent use of computers during work and involvement of machines in the life imploring for relaxation and recreation, has leads to increased rate anxiety amongst the employees. There is a dire need to make employees aware of their stress level so that when they exceed a particular level; they can get engaged at various activities provided by the software houses. Besides the old technique of using questionnaires or assessments, this stress detector would reduce the manual and conventional rhetoric.

\section{A. Motivation}

Physical and mental stress has been becoming threatening for people now a days. The worldwide survey across thousand co operations and 15 countries, commissioned by Ragus group It was determined that over past two years the stress level of working places has been marked a dismaying rise. According to the survey China has the highest level of stress at working places. Though stress has been a common part of our life, excess chronic and mental stress can rather create serious health issues for an individual. It has lead to suicides of various individuals. This emerging situation has become a challenge to human health and life quality. Hence the detection of stress, before it becomes a heinous problem is of significance importance. As the traditional psychologists say stress can be detected by interviews, questionnaires and surveys.

This research focuses on the stress detection of employees. We use questionnaire and interviewing technique to collect the data and then design a stress detector for the individuals who work on computer for more than 5 hours as a part of their work and designation. The research can help various firms and its workers to detect stress.

\section{B. Origion of Stress}

Stress stimulation depends upon two mechanisms: Alarm reaction and Adaptation. In a workplace, when individuals face any peculiar or unpredicted threat, they respond to increased muscular activity. Second is adaptation. If things do not work the way they have adapted to the workplace, this causes anxiety as well. Stress can also have two forms i.e physical and mental. In work place, using the computers particularly concerned with our study, physical stress and mental stress are both concerned. However, we evaluate the level of stress (wear and tear), the body (physical) and brain (mental), simultaneously faces over the period of time working on the computer. Stress has a background. It may be caused by a disturbance in bodily environment or mental 
working strategy of the individual. This disturbance may be due to family background.

\section{Reasons and Effects of High Stress Levels in Individuals working in Organization}

Stress in Pakistan has grown to an alarming level in the workplaces. There are various types of stress and the reasons are numerous:

Decreased Job satisfaction and motivation level of employees

- Work overload

- Time pressure

- Poor environment

- Mismanaged Organizational Structure

- Constant Work on machines and systems.

The motivational level of employees is constantly decreasing due to various other reasons. This research will focus on the one cause and depict how the awareness of stress will change the lives of individuals. Sadly, our employees these days are not aware for the reasons of their raised level of anxiety and this study will elucidate that how working on systems for a long period of time would lead to raise both physical and mental stress.

Stress has become a leading factor of causing various diseases amongst individuals. It is most common amongst youngsters and employees dissatisfied at work. Anxiety leads to various problems that can be affect memory, physique and appearance as well. The individuals who pay less heed to their raised anxiety level and do not take steps to decrease it may suffer from decreased lifetime and various health problems as well. There are several body systems getting affected immediately by stress which include blood pressure, cholesterol concentration and heart rate. The long terms effects of stress include blurred vision, coronary heart diseases, mental illness, disturbed eating patterns and mismanaged and broken families. It has become very important to not only detect but to decrease the levels of anxiety of the employees to increase the output level and ultimately raise the economy of any country. Satisfaction, happiness and better working environment is the way to get maximum output from the working individual class.

\section{LITERATURE REVIEW}

Detection of stress based on inputs has been a vital contribution to the existing society where depression has reached up to an alarming level. Many researches are there for the purpose. However, there approach is with limited parameters and majorly based on theory.

Berbano [1] discussed the detection of mental state by Electroencephalography wave analysis using Artificial Neural Network. Bilal Ahmad et al. [2] elucidates how stress has reached to maximum in Pakistan and what are the core reasons to the problem. Neil Schneiderman et al explains the singnificance of therapists and how this psychosocial interventions have lead to decreased the acute disease.[3] Sriramprakash. S et al worked on welchers algorithm for detection of stress [8].

Huijie Lin et al. [4] used social interactions, activities and behavior for detecting the stress states of the people later recommended that the user should go for health consultant or doctor. The research shows also approaches a graph which locates shortest path to the hospital. Dr Ghazala Kausar [5] beautifully depicts how women have been a victim of stress over past few years in the working environment, carrying out a survey which resulted in most of the women as a depression sufferer. The reasons, effects and solutions of anxiety at work places have also been discussed by Michie S [6]. Bhokare et al. [7] develops a magnificent system which deduces that the stress level of a person is closely related to the anxiety of the other based on mutual friendship and interactions over social media.

Ankita Tiwari, and others [9] examined on the influence of yoga before and after on the brain of patients who suffered from anxiety. They have elaborated that there is a gigantic dissimilarity between, practicing of Yoga (before \& after) and brain waves. Therefore, this is substantiated in the proposed research that yoga is straightly affecting our mental state.

A. de Santos Sierra et al. [10], have industrialized a fuzzy logic system to identify stress in real-time scenario. Most of these tactics use detailed learning or SVM to determine the level of stress of a single person. But, no description related to the data used in the training stage of these intelligent systems is provided.

A recent study [11] presents a model to detect stress centered on two vital factors namely, heart/echo rate (HR) and GSR. This system utilizes fuzzy logic to represent the vital factors. Furthermore, the stress-detection system has accuracy up to $99.5 \%$ during a period of 10 seconds.

\section{Problem Statement}

Computer based work has always been challenging and tiring. With the advent to wireless technologies and increased number of users, the use of computer has vividly increased. Computer work seems to be a part of every employee in any field. This leads to outcomes of using a computer on an individual which results in one of the alarming disease of the century i.e stress. Globally stress has been the reason of many diseases and has led to decrease productivity of the working individuals as well. This study focuses on what part does working on computer plays in increasing and adding anxiety to our lives. It will determine with the help of various inputs the level of stress of an individual. The research gives an output in the form of a signifier which reflects the specific person being in the "alarming stress" zone or not. Various factors have been taken into consideration in order to determine valid results. We focus to provide a model which aims to detect the anxiety level which could further create ways to reduce the factors which leads to this stress of employees. Keeping all the prerequisites, a working model of stress detection is provided. 


\section{METHODOLOGY}

\section{A. Working Progress}

An overview of the framework is being summarized in Fig. 1. This research being carried out with the very purpose of stress detection amongst the working class has gone through various stages before its completion. A detailed overview of what kind of work has been already done previously of stress detection was carried out where Huijie Lin et al provide a detailed framework of how social media interactions have led to increase anxiety and depression. Various others highlight the significance of stress detection which has placed an impact on the working class and yield as well. This lead to collection of data for the research work as well. A questionnaire was developed which carried out the survey of 70 employees in a software house in which their job satisfaction, no of hours working on computer and the time when they feel stressed was carried out. With the questionnaire, interviews of employees from another software house were carried out. The purpose of questionnaire and interviews was that when the data of questionnaire was taken into account, it was found out that many listed their stress level as "low" and said that they didn't notice any "kind" of stress except some physical burden while during the interviews according to their gestures, it was concluded that nearly all the employees suffered depression while working constantly for hours on computer systems in one phase or the other. After the collection of data, a model using fuzzy inference system was developed which categorized the class of employees in high low or medium stress levels.

\section{B. Proposed Model}

The raw data is taken and converted into fuzzy labels. The input variables are first converted into fuzzy label sets. From the fuzzy rule base the rules in form of if-thenare formed according to the input values and then the detection of level of stress is done. The same input variables are given in artificial neural network and the output is being used for the learning of the model. The model is represented in Fig. 2 which depicts the input variables being taken to Artificial Neural Network and the output being used for training of the system and the other inputs are used by fuzzy inference engine where the inputs are labeled. Their membership functions are defined and then rule based detects the level of stress using the previous pre-defined rules in the engine or defining some new rules according to the given particular input variation. The following steps are taken in an initial step of Fuzzification.

The data is first made into labels. For age Young (Y) and Adult (A). For input variables of Blood pressure (B.P) membership functions are created. Facial Expressions are labeled as F.E while Number of Hours working on computer is categorized in as N.O.H. The internal temperature being termed as I.E. Heart beat is taken as H.B.

Membership functions are defined with ranges of each of the variables. Table 1 depicts how the raw data is segregated in ranges.

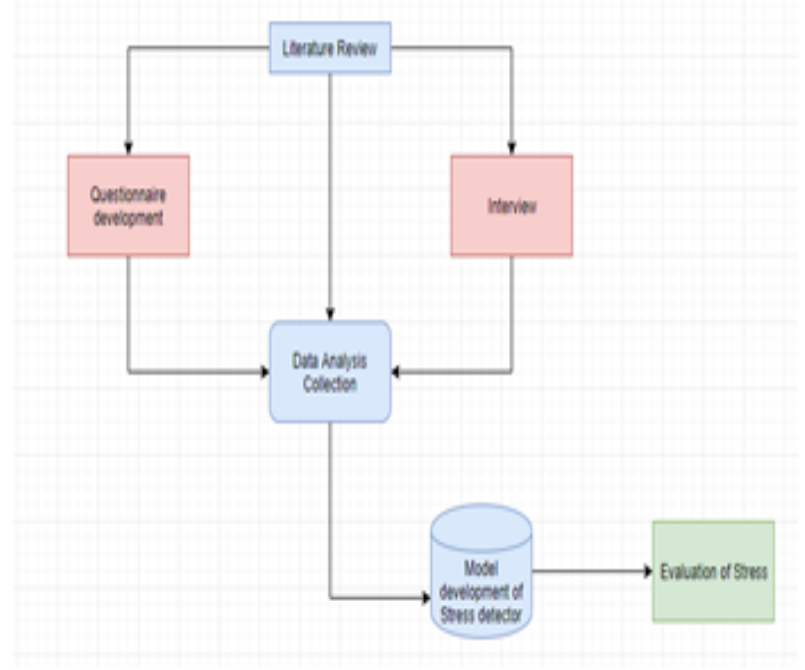

Fig. 1. Diagrammatic Summary of the Working Process.

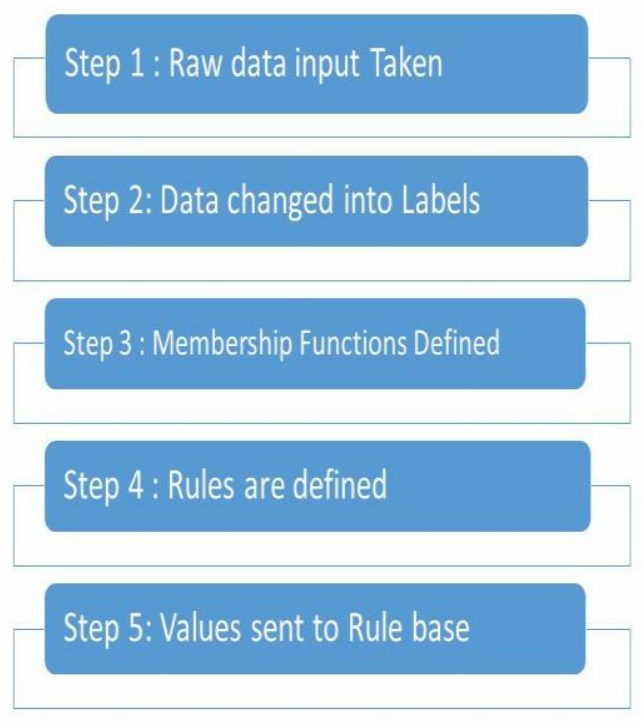

Fig. 2. An Overview of Fuzzification.

TABLE I. RANGE IDENTIFICATION OF THE RAW DATA

\begin{tabular}{|c|c|c|c|}
\hline Heart Beat & $\begin{array}{l}\text { High (90-125 } \\
\text { beats/min) }\end{array}$ & $\begin{array}{l}\text { Low }(50-70 \\
\text { beats/min) }\end{array}$ & $\begin{array}{l}\text { Medium (70-90 } \\
\text { beats/min) }\end{array}$ \\
\hline Blood Pressure & $\begin{array}{l}\text { High } \\
110-150 \mathrm{~mm} / \mathrm{Hg}\end{array}$ & $\begin{array}{l}\text { Low } \\
60-90 \mathrm{~mm} / \mathrm{Hg}\end{array}$ & $\begin{array}{l}\text { Medium } \\
80-120 \mathrm{~mm} / \mathrm{Hg}\end{array}$ \\
\hline Age & $\begin{array}{l}\text { Young } \\
15-30 \text { years }\end{array}$ & & $\begin{array}{l}\text { Adult } \\
25-50 \text { years }\end{array}$ \\
\hline $\begin{array}{l}\text { Number of } \\
\text { Hours }\end{array}$ & $\begin{array}{l}\text { High } \\
6-8 \text { hours }\end{array}$ & $\begin{array}{l}\text { Low } \\
8-10 \text { hours }\end{array}$ & $\begin{array}{l}\text { Medium } \\
10-12 \text { hours }\end{array}$ \\
\hline $\begin{array}{l}\text { Facial } \\
\text { Expressions }\end{array}$ & $\begin{array}{l}\text { Happy } \\
4-6\end{array}$ & $\begin{array}{l}\mathrm{Sad} \\
0-3\end{array}$ & $\begin{array}{l}\text { Angry } \\
6-10\end{array}$ \\
\hline $\begin{array}{l}\text { Internal } \\
\text { Temperature }\end{array}$ & $\begin{array}{l}\text { High } \\
98-100 \mathrm{~F}\end{array}$ & $\begin{array}{l}\text { Low } \\
\text { 96-97 F }\end{array}$ & $\begin{array}{l}\text { Medium } \\
97-98 \mathrm{~F}\end{array}$ \\
\hline
\end{tabular}


Table 2 shows the raw data taken from the employees and how latterly it will be converted according to the defined membership functions. After separating the ranges of the raw data, these inputs are then defined in membership functions with numerical inclusion. The values are defined and then the rule base works for the range of following data.

Then these values are placed into hundreds of if then rule i.e. fuzzy rule base.

1) If facial expressions $=$ angry then stress level $=$ high

2) If age =young, n.o.h=high, b.p=high then stress level= high

3) If age =young, n.o.h=low, b.p=low then stress level= low

4) If age =adult, n.o.h=high, i.t=high then stress level= high

5) If age =young, f.e=happy, b.p=medium then stress level $=$ medium

6) If age =young, f.e=sad, b.p=medium then stress level= medium

7) If age =young, i.t=high, b.p=medium then stress level= high

8) The obtained data is then sent to defuzzifier where these values are converted into numerical data which at the end indicate the output of stress either low, high or medium.

Fig. 3 gives a detailed overview of the model of our proposed scheme. We carried out the research via questionnaire and interviews and then using MatLab and ANFIS rule base. The results clearly indicate the stress level of the employee. The system uses ANN and is in Constant process of learning and adapting.
TABLE II. RAW DATA 25 EMPLOYEES

\begin{tabular}{|c|c|c|c|c|c|c|}
\hline Sr\# & Age & $\mathrm{NOH}$ & $B P$ & $H B$ & $F E$ & $I T$ \\
\hline$I$ & 15 & 6 & 90 & 70 & 0 & 96.1 \\
\hline 2 & 18 & 8 & 110 & 70 & 0 & 96.3 \\
\hline 3 & 30 & 10 & 87 & 70 & 1 & 96.5 \\
\hline 4 & 32 & 6 & 120 & 80 & 1 & 96.0 \\
\hline 5 & 19 & 12 & 135 & 110 & 2 & 97.3 \\
\hline 6 & 26 & 12 & 140 & 120 & 3 & 96.9 \\
\hline 7 & 28 & 6 & 147 & 90 & 5 & 98.1 \\
\hline 8 & 36 & 8 & 82 & 90 & 3 & 98.3 \\
\hline 9 & 37 & 7 & 96 & 92 & 2 & 98.5 \\
\hline 10 & 19 & 6 & 110 & 91 & 4 & 99.9 \\
\hline 11 & 22 & 7 & 100 & 76 & 2 & 96.1 \\
\hline 12 & 21 & 8 & 147 & 74 & 4 & 96.3 \\
\hline 13 & 26 & 10 & 135 & 89 & 1 & 96.5 \\
\hline 14 & 25 & 12 & 138 & 111 & 1 & 96.0 \\
\hline 15 & 24 & 12 & 141 & 123 & 6 & 97.3 \\
\hline 16 & 29 & 12 & 100 & 55 & 6 & 96.9 \\
\hline 17 & 30 & 6 & 96 & 77 & 6 & 98.1 \\
\hline 18 & 30 & 9 & 98 & 98 & 2 & 98.3 \\
\hline 19 & 31 & 6 & 95 & 124 & 3 & 98.5 \\
\hline 20 & 40 & 5 & 94 & 102 & 1 & 99.9 \\
\hline 21 & 45 & 10 & 95 & 100 & 6 & 100 \\
\hline 22 & 49 & 10 & 88 & 89 & 4 & 97.7 \\
\hline 23 & 36 & 12 & 77 & 67 & 5 & 98.9 \\
\hline 24 & 24 & 10 & 60 & 90 & 4 & 96.6 \\
\hline 25 & 23 & 12 & 68 & 110 & 5 & 97.3 \\
\hline
\end{tabular}

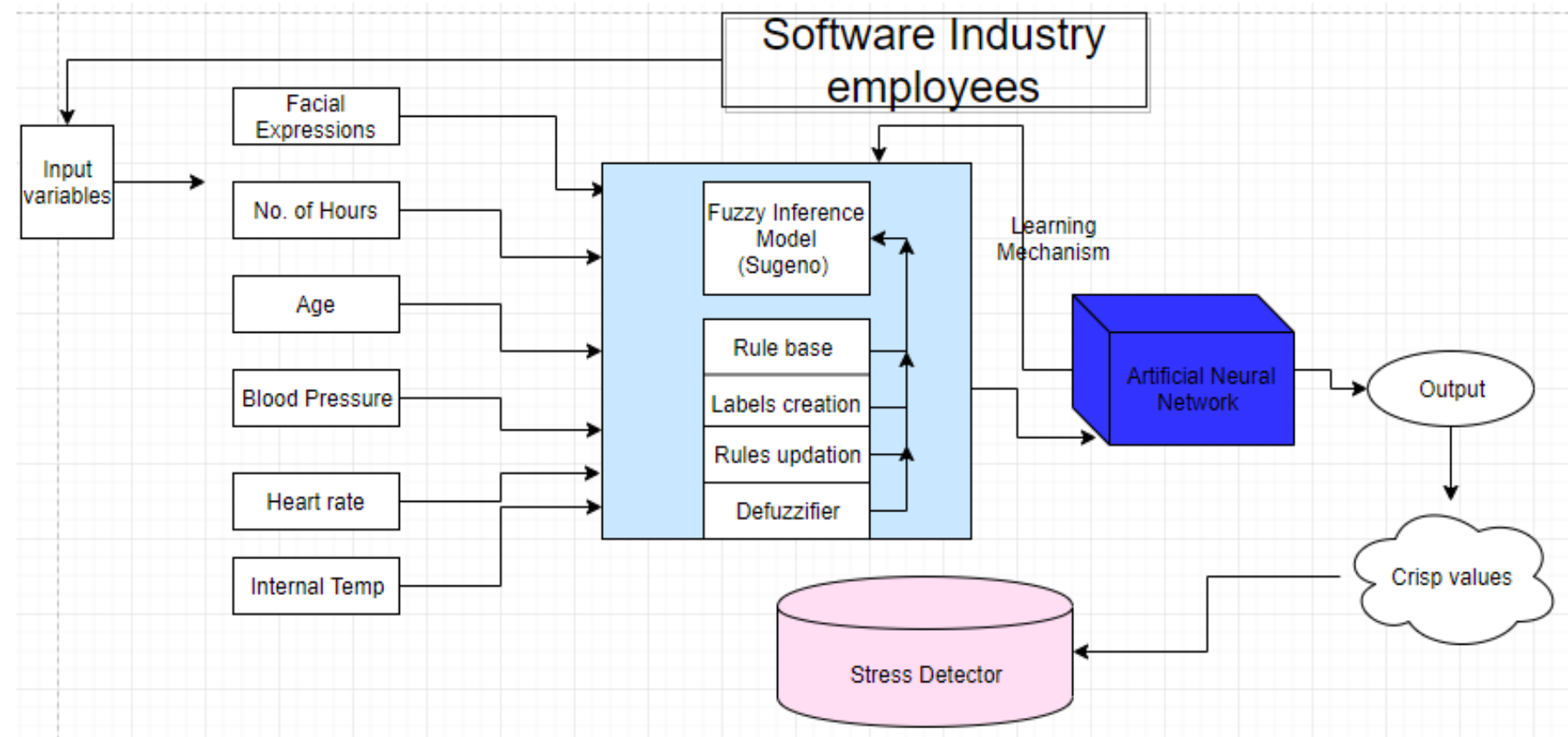

Fig. 3. Proposed Model of ANN and FIS. 


\section{RESULT AND ANALYSIS}

The main purpose of this research paper is to analysis the stress level in people working in software house and facing many problems (Physical and Health) during their hectic working time or in their life. The questionnaire is used to gather data from software houses. Some interviews are also arranged. This paper presents the extracted data of these surveys. Table 3 presents the percentage of employees which have answered the questionnaire and how they respond to interviews was different as well. 93\% of employees stated yes to the question of facing stress at work either physical or mental. Later, for those who were indicated high stress were given another set of questions represented in Table 4 which took the input for their physical conditions during the stress. Graph 1 then shows the result of factors which supported employees at work and how these factors contribute to rise or fall of stress levels. Graph 2 on contrary explains how employees engage themselves to relieve stress anxiety and depression at work via various activities.

TABLE III. QUESTIONNAIRE RESULT

\begin{tabular}{|l|l|l|}
\hline Questions & Yes & No \\
\hline Do you meet all the demand of your job? & $53 \%$ & $47 \%$ \\
\hline $\begin{array}{l}\text { Do you have any stress (due to family, work or } \\
\text { personal)? }\end{array}$ & $93 \%$ & $7 \%$ \\
\hline $\begin{array}{l}\text { Do you feel any physiological and emotional effect } \\
\text { in yourself due to stress? }\end{array}$ & $65 \%$ & $35 \%$ \\
\hline \begin{tabular}{l} 
Did you diagnose any disease due to stress? \\
\hline Are you Physically fit after your work or job?
\end{tabular} & $54 \%$ & $46 \%$ \\
\hline $\begin{array}{l}\text { Are your happy with your working hour (time } \\
\text { duration of your work)? }\end{array}$ & $68 \%$ & $65 \%$ \\
\hline $\begin{array}{l}\text { Do you have any medium for entertainment due to } \\
\text { work break to relax yourself? }\end{array}$ & $50 \%$ & $52 \%$ \\
\hline $\begin{array}{l}\text { Is your job demand from yourself over shifting } \\
\text { rather than regular time duration? }\end{array}$ & $71 \%$ & $29 \%$ \\
\hline Are you satisfied from your job? & $33 \%$ & $77 \%$ \\
\hline $\begin{array}{l}\text { Is your family or work getting affected from each } \\
\text { other? }\end{array}$ & $86 \%$ \\
\hline
\end{tabular}

TABLE IV. INPUT PARAMETERS

\begin{tabular}{|l|l|l|l|}
\hline S\# & Questions & Adult & Young \\
\hline 1. & I have blood pressure problem & $40 \%$ & $60 \%$ \\
\hline 2. & $\begin{array}{l}\text { I have back pain, headache, muscle } \\
\text { stress or neck/shoulder pain. }\end{array}$ & $50 \%$ & $50 \%$ \\
\hline 3. & $\begin{array}{l}\text { My heart rate mostly increase during } \\
\text { stressing time. }\end{array}$ & $47 \%$ & $53 \%$ \\
\hline 4. & $\begin{array}{l}\text { My pupil contraction level vary of } \\
\text { and on. }\end{array}$ & $43 \%$ & $57 \%$ \\
\hline 5. & $\begin{array}{l}\text { I often feel my Internal temperature } \\
\text { changes. }\end{array}$ & $46 \%$ & $54 \%$ \\
\hline 6. & $\begin{array}{l}\text { I fastly gain weight due to increase in } \\
\text { working hour. }\end{array}$ & $50 \%$ & $50 \%$ \\
\hline
\end{tabular}

Analysis - The factors make them to work

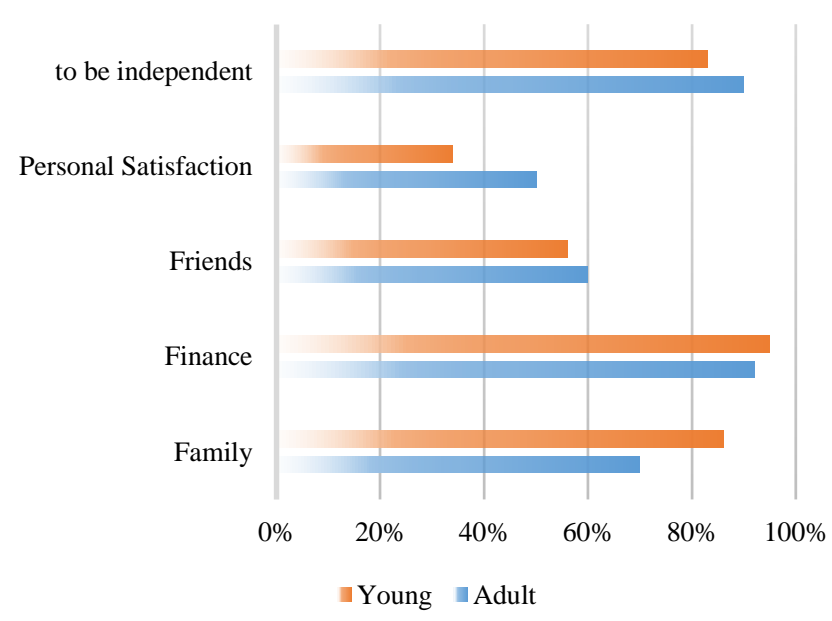

Graph. 1. Factors Supporting at Work.

Analysis - The Way People Engage themselves to Relieve Stress

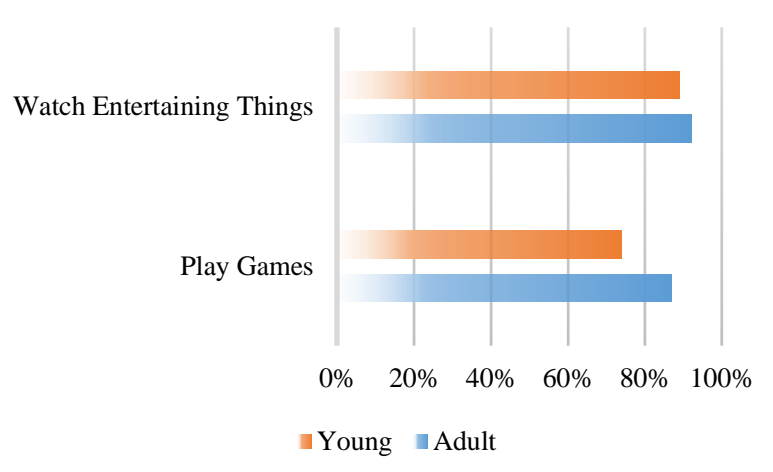

Graph. 2. Relieving Stress.

According to the survey, data of seventy five patients their working hours, pupil contractions, internal temperature, heart rate, blood pressure and facial expression was taken into account. The input values were taken as listed in Table 5. The input was then applied on ANFIS model which comprised of 150 rules and the model was trained. The training result is shown in Fig. 4. In the aftermath, the model was tested for the same data and some outlier values which then determined the error rate probability which seemed that the error decreased with increased number of iterations. The results and the model structure developed depicted in Fig. 5 and 6, respectively. Data is validated and checked on the developed system as shown in Fig. 6. The model is then checked as given in Fig. 7 and the model is then trained by giving other data inputs depicted represented by in Fig. 8. Laterly, Fuzzy inference Expert's output is generated shown in Fig. 9. This developed model is then finally tested for huge and variable data inputs once again as shown in Fig. 10. The surface model representing the inputs taken and output developed is then taken into consideration (Fig. 11). Surface viewer of fuzzy inference system can also be seen in Fig. 12. 
TABLE V. PARAMETRIC VALUES

\begin{tabular}{|c|c|c|c|c|c|c|c|}
\hline 1 & $\mathrm{FE}$ & IT & $\mathrm{NOH}$ & BP & HR & AGE & $\mathrm{OP}$ \\
\hline 2 & 0 & 97 & 8 & 150 & 70 & 15 & 59.718 \\
\hline 3 & 5 & 98 & 12 & 160 & 80 & 17 & 61.641 \\
\hline 4 & 10 & 99 & 12 & 250 & 120 & 21 & 98.398 \\
\hline 5 & 0 & 97 & 10 & 200 & 80 & 22 & 0 \\
\hline 6 & 1 & 99 & 12 & 160 & 85 & 23 & 62.022 \\
\hline 7 & 6 & 98 & 8 & 200 & 80 & 25 & 85.733 \\
\hline 8 & 0 & 98 & 12 & 210 & 858 & 27 & 0 \\
\hline 9 & 8 & 99 & 12 & 270 & 112 & 28 & 99.596 \\
\hline 10 & 2 & 98 & 11 & 230 & 100 & 35 & 8 \\
\hline 11 & 0 & 97 & 9 & 200 & 99 & 45 & 0 \\
\hline 12 & 4 & 98 & 10 & 170 & 80 & 41 & 62.662 \\
\hline 13 & 5 & 97 & 12 & 200 & 80 & 29 & 73.481 \\
\hline 14 & 8 & 98 & 12 & 230 & 98 & 50 & 82.235 \\
\hline 15 & 6 & 98 & 11 & 200 & 87 & 1 & 77.798 \\
\hline 16 & 1 & 97 & 9 & 210 & 90 & 34 & 6 \\
\hline 17 & 8 & 99 & 12 & 270 & 123 & 26 & 100.47 \\
\hline 18 & 6 & 98 & 8 & 200 & 82 & 45 & 72.571 \\
\hline 19 & 2 & 99 & 8 & 210 & 81 & 23 & 79.041 \\
\hline 20 & 10 & 99 & 12 & 260 & 122 & 24 & 96.764 \\
\hline 21 & 2 & 97 & 10 & 190 & 98 & 23 & 72.589 \\
\hline 22 & 6 & 98 & 9 & 210 & 99 & 28 & 78.302 \\
\hline 23 & 9 & 99 & 12 & 250 & 121 & 40 & 91.404 \\
\hline 24 & 1 & 97 & 8 & 105 & 100 & 27 & 49.371 \\
\hline 25 & 4 & 98 & 10 & 100 & 99 & 23 & 47.869 \\
\hline 26 & 8 & 99 & 12 & 90 & 97 & 22 & 44.881 \\
\hline 27 & 2 & 97 & 9 & 120 & 105 & 30 & 52.645 \\
\hline 28 & 4 & 99 & 8 & 129 & 106 & 32 & 54.714 \\
\hline 29 & 8 & 98 & 9 & 115 & 105 & 28 & 50.639 \\
\hline 30 & 3 & 97 & 8 & 110 & 106 & 29 & 50.776 \\
\hline 31 & 5 & 98 & 10 & 100 & 98 & 24 & 47.339 \\
\hline 32 & 9 & 99 & 12 & 100 & 80 & 22 & 43.885 \\
\hline 33 & 3 & 99 & 9 & 112 & 100 & 26 & 50.618 \\
\hline 34 & 6 & 98 & 7 & 210 & 100 & 23 & 79.325 \\
\hline 35 & 10 & 98 & 8 & 110 & 106 & 46 & 47.564 \\
\hline 36 & 3 & 97 & 9 & 110 & 106 & 35 & 6 \\
\hline 37 & 5 & 96 & 8 & 211 & 104 & 27 & 2 \\
\hline 38 & 8 & 97 & 9 & 111 & 105 & 26 & 7 \\
\hline 39 & 1 & 96 & 12 & 250 & 95 & 22 & 5 \\
\hline 40 & 6 & 98 & 13 & 201 & 96 & 24 & 2 \\
\hline 41 & 8 & 99 & 14 & 230 & 95 & 22 & 6 \\
\hline 42 & 2 & 97 & 12 & 110 & 98 & 27 & 10 \\
\hline 43 & 6 & 99 & 12 & 210 & 110 & 26 & 2 \\
\hline 44 & 10 & 97 & 13 & 105 & 111 & 24 & 8 \\
\hline 45 & 3 & 98 & 15 & 190 & 98 & 21 & 2 \\
\hline 46 & 7 & 99 & 14 & 180 & 99 & 27 & 1 \\
\hline
\end{tabular}

\begin{tabular}{|l|l|l|l|l|l|l|l|}
\hline $\mathbf{4 7}$ & 9 & 96 & 12 & 225 & 99 & 26 & 3 \\
\hline $\mathbf{4 8}$ & 1 & 97 & 13 & 115 & 99 & 25 & 8 \\
\hline $\mathbf{4 9}$ & 7 & 99 & 11 & 245 & 89 & 24 & 9 \\
\hline $\mathbf{5 0}$ & 8 & 97 & 11 & 195 & 88 & 29 & 6 \\
\hline $\mathbf{5 1}$ & 3 & 96 & 11 & 210 & 99 & 29 & 4 \\
\hline $\mathbf{5 2}$ & 7 & 97 & 14 & 215 & 90 & 28 & 3 \\
\hline $\mathbf{5 3}$ & 10 & 98 & 14 & 210 & 95 & 26 & 2 \\
\hline $\mathbf{5 4}$ & 2 & 98 & 11 & 195 & 111 & 29 & 1 \\
\hline $\mathbf{5 5}$ & 7 & 99 & 11 & 116 & 100 & 27 & 10 \\
\hline $\mathbf{5 6}$ & 9 & 96 & 13 & 111 & 105 & 24 & 9 \\
\hline $\mathbf{5 7}$ & 3 & 97 & 14 & 200 & 105 & 23 & 3 \\
\hline $\mathbf{5 8}$ & 5 & 93 & 13 & 180 & 99 & 24 & 6 \\
\hline $\mathbf{5 9}$ & 8 & 95 & 13 & 150 & 99 & 26 & 8 \\
\hline $\mathbf{6 0}$ & 1 & 99 & 12 & 190 & 98 & 22 & 6 \\
\hline $\mathbf{6 1}$ & 6 & 98 & 14 & 201 & 96 & 22 & 3 \\
\hline $\mathbf{6 2}$ & 9 & 97 & 12 & 150 & 90 & 25 & 7 \\
\hline $\mathbf{6 3}$ & 1 & 96 & 11 & 140 & 95 & 25 & 9 \\
\hline $\mathbf{6 4}$ & 5 & 99 & 11 & 240 & 95 & 24 & 7 \\
\hline $\mathbf{6 5}$ & 9 & 97 & 14 & 260 & 89 & 25 & 10 \\
\hline $\mathbf{6 6}$ & 2 & 99 & 13 & 170 & 90 & 24 & 7 \\
\hline $\mathbf{6 7}$ & 6 & 98 & 13 & 160 & 89 & 21 & 5 \\
\hline $\mathbf{6 8}$ & 10 & 95 & 14 & 108 & 90 & 23 & 7 \\
\hline $\mathbf{6 9}$ & 3 & 98 & 14 & 180 & 101 & 22 & 3 \\
\hline $\mathbf{7 0}$ & 4 & 97 & 12 & 200 & 97 & 28 & 2 \\
\hline $\mathbf{7 1}$ & 3 & 98 & 8 & 205 & 101 & 39 & 1 \\
\hline $\mathbf{7 2}$ & 5 & 98 & 9 & 225 & 80 & 21 & 3 \\
\hline $\mathbf{7 3}$ & 8 & 99 & 13 & 230 & 89 & 34 & 5 \\
\hline $\mathbf{7 4}$ & 7 & 97 & 11 & 200 & 98 & 25 & 2 \\
\hline $\mathbf{7 5}$ & 9 & 99 & 14 & 260 & 101 & 32 & 7 \\
\hline & & & & & & & \\
\hline
\end{tabular}

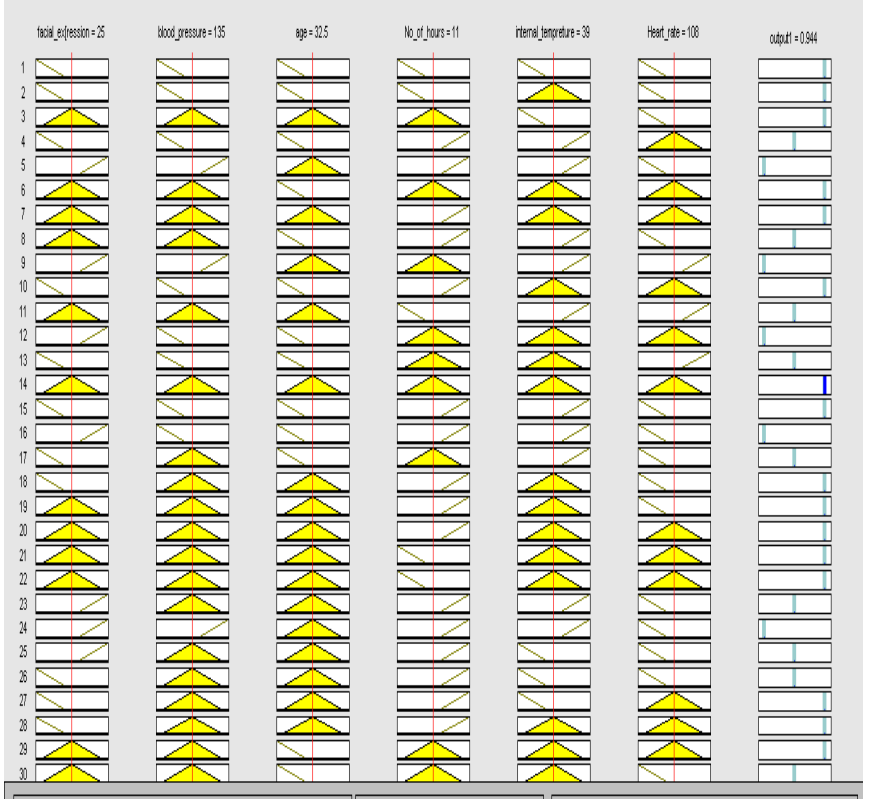

Fig. 4. Rule Viewer (Sugeno Model). 


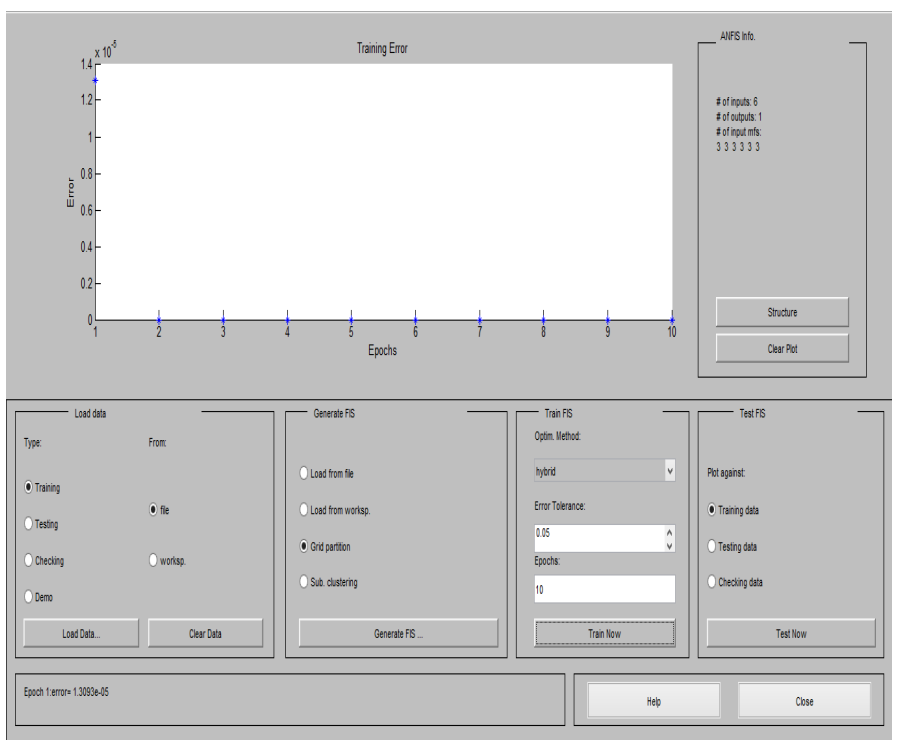

Fig. 5. Error Detection after Generating FIS.

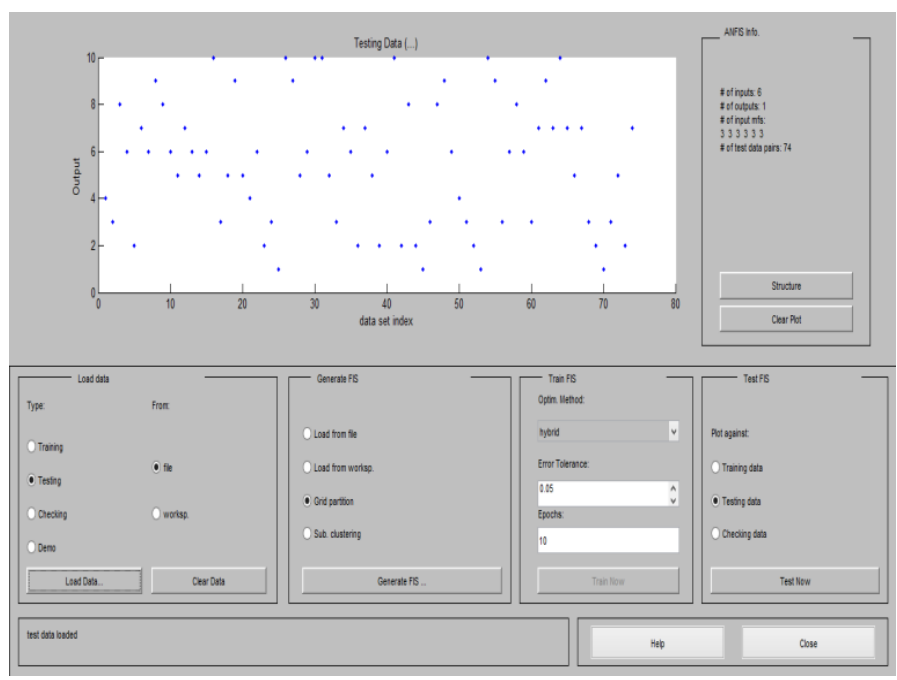

Fig. 6. Data Testing.

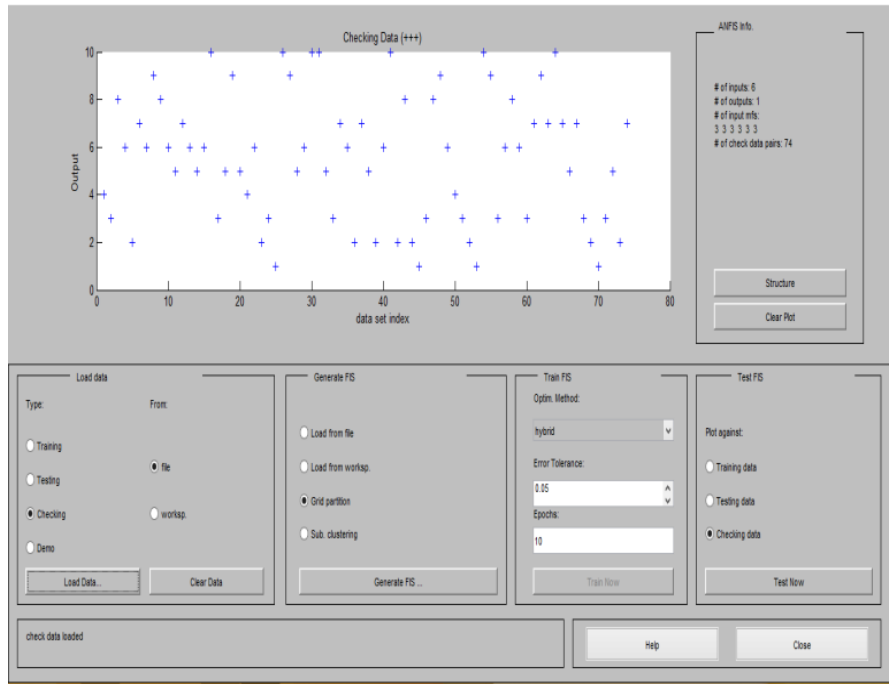

Fig. 7. Data Checking.

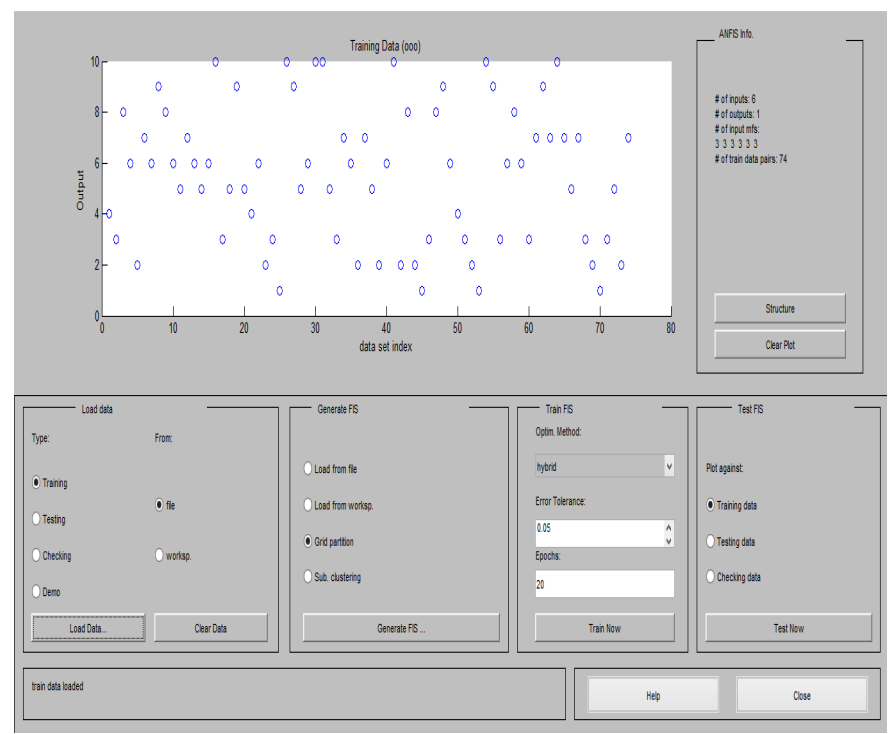

Fig. 8. Model Training

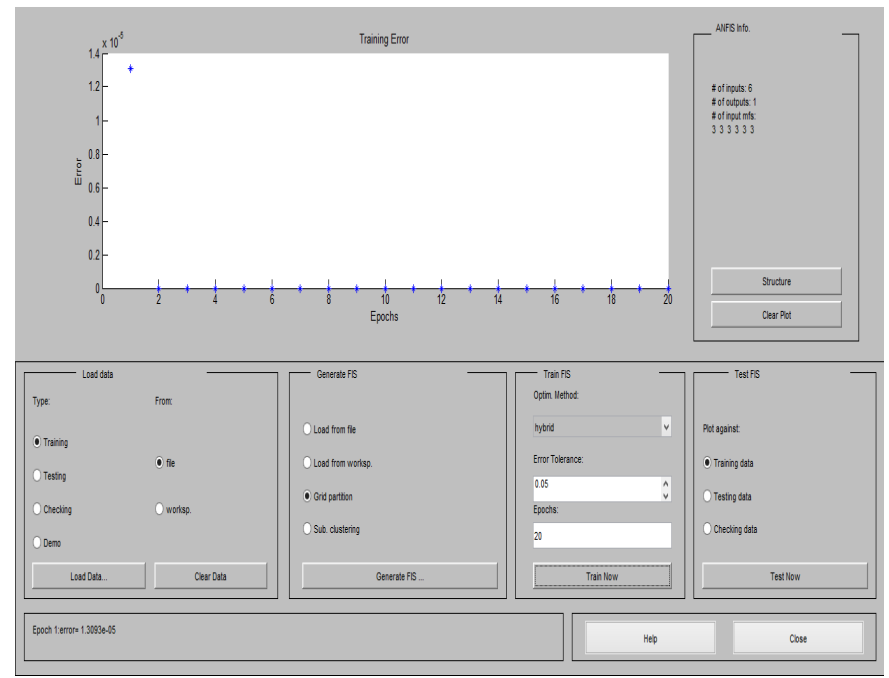

Fig. 9. Generating FIS.

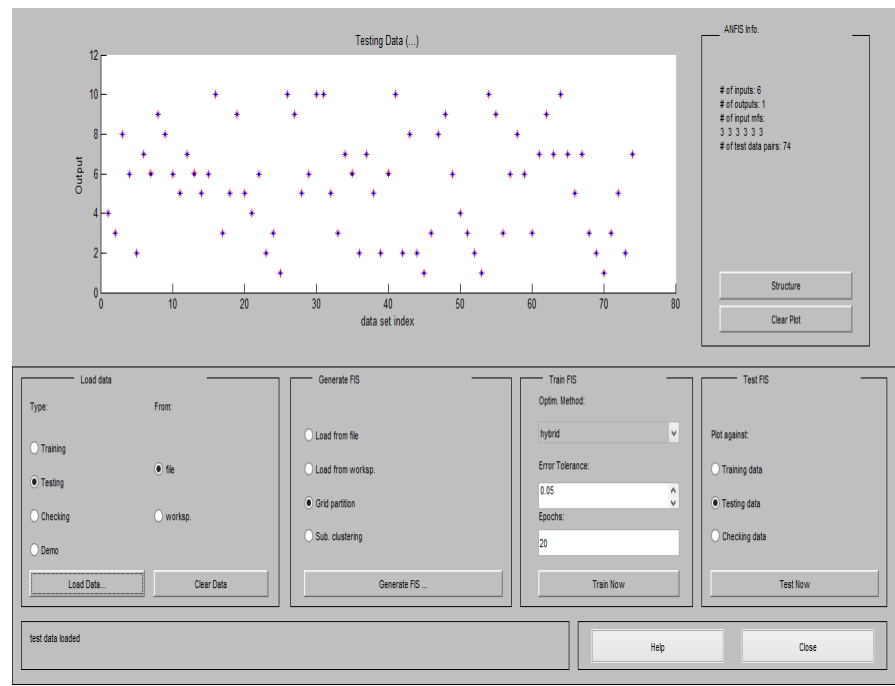

Fig. 10. Data Testing. 


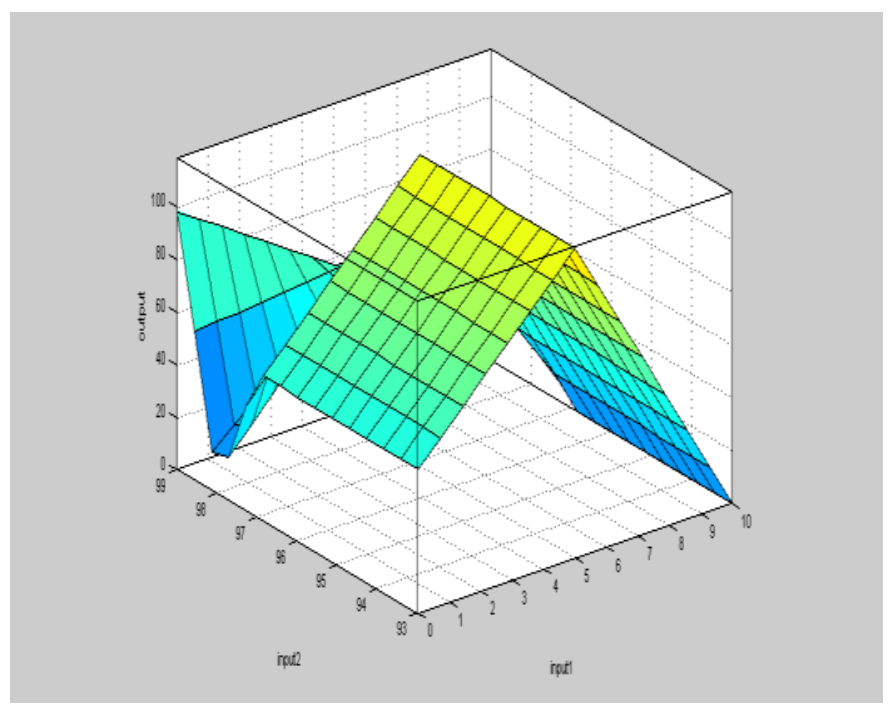

Fig. 11. Surface Model.

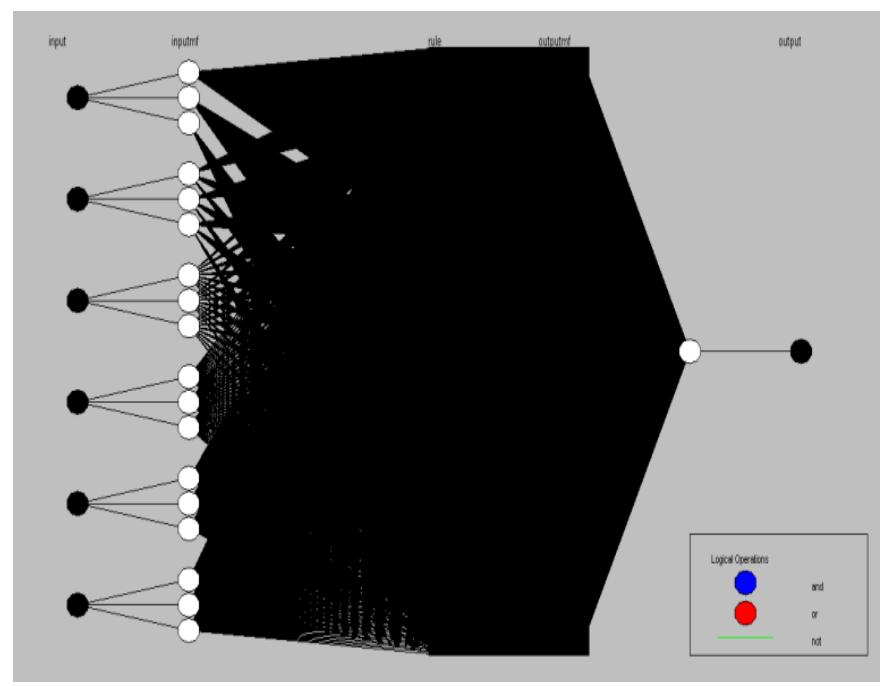

Fig. 12. Formula Structure.

\section{CONCLUSION}

The research contributes to develop an expert system which determines the stress level of employees working in computer industries. An ANFIS model is designed to obtain the output and train the fuzzy system according to change. It can be implemented as an automated system in industries like software houses and computer related universities where people are bound to work. The model could deduce the stress level of the working class and hence the organization could develop some relieving activities for its employees. Moreover, the employees themselves can perform a little exercise while sitting and looking on computer for hours. This model would create an awareness of stress level which could contribute to decrease the depression hence increasing innovation and developing a healthy working environment.

\section{REFERENCES}

[1] Berbano, A. E. (2017). Classification of Stress into Emotional, Mental,. Proc. of the 2017, IEEE International Conference on Signal and Image Processing Applications (pp. 11-13). Malaysia: IEEE.

[2] AL., B. A. (2016). Depression and anxiety: a snapshot of the situation. International Journal of Neuroscience and Behavioral Science 4, 32-36.

[3] Neil Schneiderman, G. I. (2016). STRESS AND HEALTH: Psychological, Behavioral, and Biological Determinants. HHS Public access , 607-628.

[4] AL., H. L. (2014). Detecting Stress Based on Social Interactions in Social Networks. IEEE JOURNAL OF LATEX CLASS FILES , 1-14.

[5] AL., D. G. (2015). Stress in Pakistani Working Women . Journal of Culture, Society and Development , 58-65.

[6] Michie, S. (2002). CAUSES AND MANAGEMENT OF STRESS AT WORK. Occup Environ Med , 67-72.

[7] Taki Ravikant Bhokare, P. e. (2018). Survey Paper Detecting Stress of users on Social Interactions on Social networks. International Journal of Innovative Research in Science, , 337-341

[8] AL., S. e. (2017). Stress Detection in Working People. Science Direct , 359-66.

[9] AL, A. D. (2016). Determining the Stress level. IJERT , 28-39.

[10] AL, A. d. (2011). Real-Time Stress Detection. Intech Open science , 23 44.

[11] AL, A. T. (2017). Monitoring and Detection of EEG Signals. IEEE , 329-335. 